\title{
Extended doxycycline treatment versus salpingectomy in the management of patients with hydrosalpinx undergoing IVF-ET
}

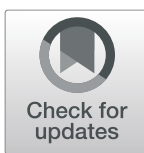

Usama M. Fouda ${ }^{1,2^{*}} \mathbb{D}$, Hesham S. Elshaer ${ }^{1,2}$, Mohamed A. Youssef ${ }^{1}$ and Fatma F. Darweesh ${ }^{1,2}$

\begin{abstract}
Background: The aim of this study was to determine whether the treatment with doxycycline before and after oocyte retrieval is as effective as salpingectomy in minimizing the detrimental effect of hydrosalpinx on the outcomes of IVF-ET.

Methods: A retrospective analysis was done for the outcomes of the IVF-ET cycles of patients with hydrosalpinx who underwent laparoscopic salpingectomy prior to IVF cycle $(n=260)$ or were treated with extended doxycycline treatment during the IVF cycle $(n=45)$. In doxycycline group, doxycycline (100 mg twice daily) was started 1 week before anticipated oocyte retrieval and was continued for 1 week after oocyte retrieval. In salpingectomy group, the mesosalpinx was coagulated as close as possible to the fallopian tube.

Results: The implantation, clinical pregnancy, ongoing pregnancy and live birth rates were significantly higher in the salpingectomy group $(20.87 \%$ Vs. $9.91 \%, P$ value $=0.007,44.62 \%$ Vs. $20 \%, P$ value $=0.002,39.62 \%$ Vs. $17.78 \%, P$ value $=0.005$ and $37.31 \%$ Vs. $15.56 \%, P$ value $=0.005$ respectively).

Conclusion: Salpingectomy is more effective than extended doxycycline treatment in improving the outcomes of IVF-ET in patients with hydrosalpinx undergoing IVF-ET. Further, larger well designed randomized controlled trials should be conducted to confirm the findings of this study.
\end{abstract}

Keywords: Salpingectomy, Doxycycline, Hydrosalpinx, IVF-ET, Infertility

\section{Introduction}

The negative consequences of hydrosalpinx on the outcomes of IVF-ET are confirmed by an overwhelming scientific evidence [1, 2]. A meta-analyses including 5592 patients with tubal factor of infertility (1004 with hydrosalpinx and 4588 without hydrosalpinx) revealed that the implantation, pregnancy and delivery rates were significantly lower in hydrosalpinx group (8.5\% Vs. $13.7 \%$, $19.7 \%$ Vs. $31.2 \%, \quad 13.4 \%$ Vs. $23.4 \%$ respectively).

\footnotetext{
* Correspondence: umfrfouda@yahoo.com

'Department of Obstetrics and Gynecology, Faculty of Medicine, Cairo University, Kasr Al-Ainy Hospital, Al-Saraya Street, Cairo, Egypt

${ }^{2}$ Riyadh Fertility and Reproductive Health Center, Giza, Egypt
}

Moreover, the miscarriage rate was significantly higher in hydrosalpinx group (43.7\% Vs. 31.1\%) [3].

Since 1994, there is almost agreement between studies that salpingectomy or proximal tubal occlusion significantly improve the reproductive outcomes of IVF-ET [1, $4,5]$. A Cochrane review revealed that salpingectomy or proximal tubal occlusion prior to IVF-ET significantly increased the clinical pregnancy, ongoing pregnancy and live birth rates [6]. However, salpingectomy or proximal tubal occlusion are invasive procedures that may be associated with peri-operative complications especially in patients with dense pelvic adhesions. Moreover, some patients decline to undergo bilateral salpingectomy or

(c) The Author(s). 2020 Open Access This article is licensed under a Creative Commons Attribution 4.0 International License, which permits use, sharing, adaptation, distribution and reproduction in any medium or format, as long as you give appropriate credit to the original author(s) and the source, provide a link to the Creative Commons licence, and indicate if changes were made. The images or other third party material in this article are included in the article's Creative Commons. licence, unless indicated otherwise in a credit line to the material. If material is not included in the article's Creative Commons licence and your intended use is not permitted by statutory regulation or exceeds the permitted use, you will need to obtain permission directly from the copyright holder. To view a copy of this licence, visit http://creativecommons.org/licenses/by/4.0/ The Creative Commons Public Domain Dedication waiver (http://creativecommons.org/publicdomain/zero/1.0/) applies to the data made available in this article, unless otherwise stated in a credit line to the data. 
tubal occlusion because these procedures remove any possibility of spontaneous pregnancy.

Other less invasive and safer treatment modalities for patients with hydrosalpinx undergoing IVF-ET include ultrasound guided aspiration of hydrosalpinx fluid and hysteroscopic occlusion of fallopian tube with Essure micro-inserts. Although the initial results of these treatment modalities are promising, their routine use in the management of patients with hydrosalpinx undergoing IVF-ET is not recommended because their supporting evidence was obtained from small studies [7-9]. Moreover, ultrasound guided aspiration of hydrosalpingeal fluid may cause flaring of pelvic infection or injury of bowel and cannot be used in patients with hydrosalpinges which are not visible by ultrasound. Similarly, hysteroscopic occlusion of fallopian tube with Essure micro-inserts delays IVF cycle, may cause injury of uterus and may be associated with long term complications such as menstrual irregularities, allergy and chronic pelvic pain [7-9].

A small retrospective study has revealed that the reproductive outcomes of IVF-ET cycles were comparable in patients with hydrosalpinx treated with doxycycline (100 mg twice daily 1 week before expected oocyte retrieval and continued until 6 days after oocyte retrieval) versus patients with tubal occlusion/adhesion and patients with endometriosis/unexplained infertility [10].

The aim of this study was to determine whether the treatment with doxycycline before and after oocyte retrieval is as effective as salpingectomy in minimizing the detrimental effect of hydrosalpinx on the outcomes of IVF-ET.

\section{Materials and methods}

We conducted a retrospective analysis for the outcomes of the IVF-ET cycles of patients with hydrosalpinx who underwent salpingectomy prior to the IVF cycle $(n=260)$ or were treated with extended doxycycline treatment during the IVF cycle $(n=45)$ in Riyadh fertility and reproductive health center during the period between 2012 and 2017. Laparoscopic salpingectomy was offered to all the patients with hydrosalpinx diagnosed with hysterosalpingography or laparoscopy. Patients who declined surgery or have extensive pelvic adhesions or have history of multiple laparotomies underwent ultrasound guided aspiration of hydrosalpingeal fluid or received doxycycline treatment.

In doxycycline group, doxycycline (100 mg twice daily) was started 7 days before anticipated oocyte retrieval and was continued for 7 days after oocyte retrieval. In laparoscopic salpingectomy group, the mesosalpinx was coagulated as near as possible to the fallopian tube using bipolar diathermy. IVF-ET cycles were started at least 2 months after salpingectomy. The first attempt fresh IVF-ET cycles after salpingectomy were included in the analysis.
Patients with age more than 37 years, anti-Müllerian hormone $(\mathrm{AMH}) \leq 0.3 \mathrm{ng} / \mathrm{ml}$, antral follicle count $(\mathrm{AFC})<6$, uterine fibroid requiring surgical removal, endometriosis and history of recurrent miscarriage, were excluded from the study. Patients were informed about the possibility of using their medical records in research and they did not refuse. Ethics committee approved the protocol of the study. The patients were contacted to obtain their consent for the retrospective study.

A long GnRH agonist protocol using triptorelin (Triptofem, Karmed HandelsgesmbH, Austria) at a daily dose of $1 \mathrm{mg}$ s.c was started 7 days before the anticipated date of the menstruation. Once pituitary down-regulation was achieved (confirmed by the absence of cysts in ovary, endometrial thickness less than $5 \mathrm{~mm}$, serum estradiol less than $50 \mathrm{pg} / \mathrm{ml}$ ), the dose of triptorelin was reduced to $0.5 \mathrm{mg}$ and ovarian stimulation with highly purified urinary FSH (HP-uFSH) (Fostimon, IBSA, Switzerland) was started on cycle day 2 or 3 . The starting dose of HP-uFSH varied from $150 \mathrm{IU} /$ day to $300 \mathrm{IU} /$ day depending on the age of the patient, AMH level, basal FSH level and antral follicle count. After the fifth stimulation day, the dose of HP-uFSH was adjusted according to the ovarian response. Human chorionic gonadotropin (HCG) (Pregnyl; N.V.Organon, Oss, Holland) at dose of 10,000 IU was administered intramuscularly when there were at least 3 follicles $\geq 17 \mathrm{~mm}$ in mean diameter. Ovum pickup was carried out by ultrasoundguided follicular fluid aspiration $36 \pm 2 \mathrm{~h}$ after HCG administration.

A maximum of 3 embryos were transferred 3 to 5 days after ovum pickup. Pregnancy test was performed 2 weeks after embryo transfer and ultrasound examination was performed 5 weeks after embryo transfer to determine the number of gestational sacs inside uterus and to detect the presence of fetal cardiac activity [11]. Progesterone vaginal suppository (Prontogest, Marcyrl, Egypt) was administered at a daily dose of $800 \mathrm{mg}$ for luteal phase support.

\section{Statistical analysis}

Student $\mathrm{t}$ test was used to compare quantitative variables and Chi-square $\left(x^{2}\right)$ test was used to compare categorical data. Yates correction equation was used instead of Chi-square $\left(x^{2}\right)$ test when the expected frequency was less than 5 . A probability value ( $p$ value) $<0.05$ was considered statistically significant. Statistical calculations were performed using Microsoft Excel version 7 (Microsoft Corporation, NY).

\section{Results}

There were no significant differences between both groups with respect to age, body mass index, basal FSH, type and duration of infertility, percentage of patients 
with bilateral hydrosalpinx and percentage of patients with ultrasound visible hydrosalpinx (Table 1).

Table 2 shows the cycle characteristics in both groups. The stimulation period, total dose of HP-uFSH, number of follicles $\geq 17 \mathrm{~mm}$ on the day of HCG administration, oocytes retrieved, metaphase II oocyte, 2 pro-nucleate (2PN) embryos and number of embryos transferred were comparable between both groups.

The implantation, clinical pregnancy, ongoing pregnancy and live birth rates were significantly higher in the salpingectomy group $(20.87 \%$ Vs. $9.91 \%, P$ value $=0.007$, $44.62 \%$ Vs. $20 \%, P$ value $=0.002,39.62 \%$ Vs. $17.78 \%, P$ value $=0.005$ and $37.31 \%$ Vs. $15.56 \%, P$ value $=0.005$ respectively). The abortion rate was comparable between both groups $(11.21 \%$ Vs. $11.11 \%, P$ value $=0.993)$ (Table 3). Seven patients in doxycycline group have uterine fluid collection on the day of embryo transfer. No pregnancies occurred in those patients. None of the patients in salpingectomy group had uterine fluid collection on the day of embryo transfer.

None of the patients in salpingectomy group had perioperative complications and none of the patients in the doxycycline group had adverse drug effects.

\section{Discussion}

The data presented in the current study revealed that salpingectomy is more effective than extended doxycycline treatment during IVF-ET cycle in improving the outcomes of IVF-ET in patients with hydrosalpinx undergoing IVF-ET.

The results of the current study indicate that the extended doxycycline treatment is not effective in minimizing the detrimental effect of hydrosalpinx on the outcomes of IVF-ET. In contrast to our findings, a

Table 1 Patients' characteristics

\begin{tabular}{|c|c|c|c|}
\hline & $\begin{array}{l}\text { Salpingectomy } \\
\text { group } \\
(\boldsymbol{n}=260)\end{array}$ & $\begin{array}{l}\text { Doxycycline } \\
\text { group } \\
(\boldsymbol{n}=45)\end{array}$ & $\boldsymbol{P}$ value \\
\hline Age (years) & $27.65 \pm 3.55$ & $28.31 \pm 3.71$ & 0.274 \\
\hline $\begin{array}{l}\text { Body mass index } \\
\left(\mathrm{Kg} / \mathrm{m}^{2}\right)\end{array}$ & $26.17 \pm 3.018$ & $26.44 \pm 3.35$ & 0.608 \\
\hline $\begin{array}{l}\text { Duration of infertility } \\
\text { (years) }\end{array}$ & $3.54 \pm 1.82$ & $3.27 \pm 1.72$ & 0.337 \\
\hline \multicolumn{4}{|l|}{ Type of infertility } \\
\hline - Primary & $212 / 260(81.54 \%)$ & $33 / 45$ (73.33\%) & 0.201 \\
\hline - Secondary & $48 / 260(18.46 \%)$ & $12 / 45(26.67 \%)$ & 0.201 \\
\hline Basal FSH (IU/L) & $6.3 \pm 2.01$ & $6.19 \pm 2.07$ & 0.749 \\
\hline $\begin{array}{l}\text { Bilateral } \\
\text { hydrosalpinx }\end{array}$ & $52 / 260(20 \%)$ & $10 / 45(22.22 \%)$ & 0.732 \\
\hline $\begin{array}{l}\text { Hydrosalpinx visible } \\
\text { by U/S }\end{array}$ & $121 / 260(46.54 \%)$ & $23 / 45(51.11 \%)$ & 0.571 \\
\hline
\end{tabular}

Values are expressed as mean \pm SD or $n / n(\%)$

U/S Ultrasound retrospective study comparing the reproductive outcomes of IVF-ET cycles of 17 patients with hydrosalpinx treated with extended doxycycline treatment with the reproductive outcomes of IVF-ET cycles of 25 patients with adhesions/proximal tubal occlusion, and 22 patients with endometriosis/unexplained infertility revealed that the implantation and live birth rates were comparable between the three groups. The authors suggested that antibiotic treatment could prevent the detrimental impact of hydrosalpinx on the outcomes of IVF-ET [10].

In the current study, no pregnancies occurred in 7 patients in the doxycycline group who have uterine fluid collection on the day embryo transfer. The results of our study are in agreement with several studies which revealed that the patients with hydrosalpinx and uterine fluid collection on the day embryo transfer have almost no chance of pregnancy if embryos are transferred [12-14].

Hydrosalpinx is a chronic pathological condition characterized by accumulation of clear watery fluid in the fallopian tube due to obstruction of the distal end of the fallopian tube. Obstruction of the distal end of fallopian tube usually occur as a result of acute salpingitis. Other rare causes of obstruction of distal end of fallopian tube include endometriosis, appendicitis or pelvic adhesions $[1,2]$.

Several theories have been proposed to explain the association between hydrosalpinx and poor outcomes of IVF-ET. Several authors proposed that the leakage of hydrosalpingeal fluid into the uterine cavity may exert an embryotoxic effect, alter endometrial receptivity or mechanically wash the embryos [15-17].

Although the majority of studies documented the toxicity of hydrosalpingeal fluid on mouse embryos [15], several studies revealed that the hydrosalpingeal fluid has no adverse effect on human embryos development [16, 17].

One theory suggested that the inflammation of the hydrosalpinx (caused by Chlamydia trachomatis or other bacteria) is the main cause of the detrimental effect of hydrosalpinx on the outcomes of IVF-ET. Consequently, antibiotics (particularly those effective against Chlamydia trachomatis) were used to prevent this detrimental effect [10].

Several authors suggested that cytokines, prostaglandins, leukotrienes and reactive oxygen species produced by chronic inflammatory cells associated with hydrosalpinx could have an embryotoxic effect $[18,19]$. Moreover, simultaneous acute salpingitis and acute endometritis often occur in patients with acute pelvic inflammatory disease (PID), puerperal sepsis or post abortion infections. Hydrosalpinx and chronic endometritis are common sequels of acute salpingitis and acute endometritis respectively [20]. Several studies revealed that chronic endometritis can cause recurrent implantation 
Table 2 IVF cycle characteristics

\begin{tabular}{llll}
\hline & $\begin{array}{l}\text { Salpingectomy group } \\
(\boldsymbol{n}=260)\end{array}$ & $\begin{array}{l}\text { Doxycycline group } \\
(\boldsymbol{n}=45)\end{array}$ & $\begin{array}{l}\boldsymbol{P} \text { value } \\
\text { Stimulation period (days) }\end{array}$ \\
Consumed HP-uFSH units & $11.16 \pm 3.52$ & $11.53 \pm 1.71$ & 0.42 \\
Follicles $\geq 17$ mm on the day of HCG administration & $2596 \pm 502$ & $2708 \pm 650$ & 0.278 \\
Retrieved oocytes & $11.16 \pm 3.52$ & $11.89 \pm 4.68$ & 0.324 \\
Metaphase II oocytes & $10.13 \pm 3.2$ & $10.64 \pm 4.69$ & 0.479 \\
Two pronucleate embryos & $8.7 \pm 3.25$ & $8.53 \pm 3.23$ & 0.76 \\
Fertilization rate & $6.70 \pm 2.63$ & $6.96 \pm 3.91$ & 0.68 \\
No. of embryos transferred & $1609 / 2087(77.1 \%)$ & $313 / 384(81.51 \%)$ & 0.056 \\
Grade I \& II embryos /transferred embryos & $2.59 \pm 0.49$ & $2.47 \pm 0.55$ & 0.146 \\
\hline
\end{tabular}

Values are expressed as mean \pm SD or $n / n(\%)$

failure and that antibiotic treatment of chronic endometritis could improve the uterine receptivity [21, 22].

Several studies revealed that the expression of markers of endometrial receptivity (alpha $\mathrm{v}$ beta 3 and leukaemia inhibitory factor) was significantly decreased at the time of the implantation window in patients with hydrosalpinx and that the expression of these markers was significantly increased after salpingectomy [23, 24]. The results of these studies explained the mechanism by which hydrosalpinx exerts its detrimental effect on the outcomes of IVF-ET and confirmed that salpingectomy can prevent this effect.

The main limitations of the current study are the retrospective design and the small sample size. However, to the best of our knowledge the current study is the largest study which evaluated the effect of extended doxycycline treatment before and after oocyte retrieval on the outcomes of IVF-ET cycles in patients with hydrosalpinx. Moreover, the current study is the first study which compared salpingectomy with extended doxycycline treatment before and after oocyte retrieval in the management of patients with hydrosalpinx undergoing IVF-ET.

Table 3 Reproductive outcomes

\begin{tabular}{|c|c|c|c|}
\hline & $\begin{array}{l}\text { Salpingectomy } \\
\text { group } \\
(\boldsymbol{n}=260)\end{array}$ & $\begin{array}{l}\text { Doxycycline } \\
\text { group } \\
(\boldsymbol{n}=45)\end{array}$ & $\boldsymbol{P}$ value \\
\hline $\begin{array}{l}\text { Clinical pregnancy } \\
\text { rate }\end{array}$ & $116 / 260(44.62 \%)$ & $9 / 45(20 \%)$ & 0.002 \\
\hline $\begin{array}{l}\text { Ongoing pregnancy } \\
\text { rate }\end{array}$ & $103 / 260$ (39.62\%) & $8 / 45(17.78 \%)$ & 0.005 \\
\hline Live birth rate & $97 / 260(37.31 \%)$ & $7 / 45$ (15.56\%) & 0.005 \\
\hline Implantation rate & $130 / 623(20.87 \%)$ & $11 / 111$ (9.91\%) & 0.007 \\
\hline $\begin{array}{l}\text { Spontaneous abortion } \\
\text { rate } n / I U P\end{array}$ & $13 / 116(11.21 \%)$ & $1 / 9(11.11 \%)$ & 0.993 \\
\hline
\end{tabular}

Values are expressed as $\mathrm{n} / \mathrm{n}(\%)$

IUP Intrauterine pregnancy

\section{Conclusion}

In conclusion, salpingectomy is more effective than extended doxycycline treatment in improving the outcomes of IVF-ET in patients with hydrosalpinx undergoing IVF-ET. Further, larger well designed randomized controlled trials should be conducted to confirm the findings of this study.

Abbreviations

AFC: Antral follicle count; AMH: Anti-Müllerian hormone; FSH: Follicle stimulating hormone; ICSI: Intra cytoplasmatic sperm injection; IVF-ET: In vitro fertilization embryo transfer; IUP: Intrauterine pregnancy; PID: Pelvic inflammatory disease; U/S: Ultrasound

\section{Acknowledgements}

No acknowledgements.

Authors' contributions

Each author made substantial contributions to the conception, design of the work; the acquisition, analysis, interpretation of data, drafted the work and substantively revised it. The authors read and approved the final manuscript.

Funding

No grants.

Availability of data and materials

The datasets used and/or analysed during the current study are available from the corresponding author on reasonable request.

Ethics approval and consent to participate

Ethics committee of Riyadh fertility and reproductive health center approved the protocol of the study.

Informed consent was obtained from all individual participants included in the study.

Consent for publication

Not applicable.

Competing interests

The authors declare that they have no competing interests.

Received: 20 April 2020 Accepted: 24 May 2020

Published online: 12 June 2020

References

1. Andersen AN, Yue Z, Meng FJ, Petersen K. Low implantation rate after invitro fertilization in patients with hydrosalpinges diagnosed by ultrasonography. Hum Reprod. 1994;9:1935-8. 
2. Strandell A, Waldenstrom U, Nilsson L, Hamberger L. Hydrosalpinx reduces in-vitro fertilization/embryo transfer pregnancy rates. Hum Reprod. 1994;9: 861-3.

3. Camus E, Poncelet C, Goffinet F, Wainer B, Merlet F, Nisand I, et al. Pregnancy rates after in-vitro fertilizationin cases of tubal infertility with and without hydrosalpinx:a meta-analysis of published comparative studies. Hum Reprod. 1999;14:1243-9.

4. Shelton KE, Butler L, Toner JP, Oehninger S, Muasher SJ. Salpingectomy improves the pregnancy rate in in-vitro fertilization patients with hydrosalpinx. Hum Reprod. 1996;11:523-5.

5. Strandell A, Lindhard A, Waldenstrom U, Thorburn J, Janson PO, Hamberger L. Hydrosalpinx and IVF outcome: a prospective, randomized multicentre trial in Scandinavia onsalpingectomy prior to IVF. Hum Reprod. 1999;14: 2762-9.

6. Johnson NP, Mak W, Sowter MC. Laparoscopic salpingectomy for women with hydrosalpinges enhances the success of IVF: a Cochrane review. Hum Reprod. 2002;17:543-8.

7. Fouda UM, Sayed AM. Effect of ultrasound-guided aspiration of hydrosalpingeal fluid during oocyte retrieval on the outcomes of in vitro fertilisation-embryo transfer: a randomised controlled trial (NCT01040351). Gynecol Endocrinol. 2011;27(8):562-7.

8. Hitkari JA, Singh SS, Shapiro HM, Leyland N. Essure treatment of hydrosalpinges. Fertil Steril. 2007;88:1663-6.

9. D'Arpe S, Franceschetti S, Caccetta J, Pietrangeli D, Muzii L, Panici PB. Management of hydrosalpinx before IVF: a literature review. J Obstet Gynaecol. 2015;35(6):547-50.

10. Hurst BS, Tucker KE, Awoniyi CA, Schlaff WD. Hydrosalpinx treated with extended doxycycline does not compromise the success of in vitro fertilization. Fertil Steril. 2001;75:1017-9.

11. Fouda $U$, Sayed A. Extended high dose letrozole regimen versus short low dose letrozole regimen as an adjuvant to gonadotropin releasing hormone antagonist protocol in poor responders undergoing IVF-ET*. Gynecol Endocrinol. 2011;27(12):1018-22.

12. Chien LW, Au HK, Xiao J, Tzeng CR. Fluid accumulation within the uterine cavity reduces pregnancy rates in women undergoing IVF. Hum Reprod. 2002;17:351-6

13. Akman MA, Erden HF, Bahceci M. Endometrial fluid visualized through ultrasonography during ovarian stimulation in IVF cycles impairs the outcome in tubal factor, but not PCOS, patients. Hum Reprod. 2005:20:906-9.

14. Fouda UM, Sayed AM, Abdelmoty HI, Elsetohy KA. Ultrasound guided aspiration of hydrosalpinx fluid versus salpingectomy in the management of patients with ultrasound visible hydrosalpinx undergoing IVF-ET: a randomized controlled trial. BMC Womens Health. 2015;15:21.

15. Ajonuma LC, Ng EH, Chan HC. New insights into the mechanisms underlying hydrosalpinx fluid formation and its adverse effect on IVF outcome. Hum Reprod Update. 2002;8(3):255-64.

16. Strandell A, Sjogren A, Bentin-Ley U, Thorburn J, Hamberger L, Brannstrom M. Hydrosalpinx fluid does not adversely affect the normal development of human embryos and implantation in vitro. Hum Reprod. 1998;13:2921-5.

17. Granot I, Dekel N, Segal I, Fieldust S, Shoham Z, Barash A. Is hydrosalpinx fluid cytotoxic? Hum Reprod. 1998;13(6):1620-4.

18. David A, Garcia CR, Czernobilsky B. Human hydrosalpinx. Histologic study and chemical composition of fluid. Am J Obstet Gynecol. 1969;105(3):400-11.

19. Bedaiwy MA, Goldberg JM, Falcone T, Singh M, Nelson D, Azab H, et al. Relationship between oxidative stress and embryotoxicity of hydrosalpingeal fluid. Hum Reprod. 2002;17(3):601-4.

20. Eckert LO, Hawes SE, Wölner-Hanssen PK, Kiviat NB, Wasserheit JN, Paavonen JA, et al. Endometritis. The clinical-pathologic syndrome. Am J Obstet Gynecol. 2002;186:690-5.

21. Kitaya K, Matsubayashi H, Takaya Y, Nishiyama R, Yamaguchi K, Takeuchi T, et al. Live birth rate following oral antibiotic treatment for chronic endometritis in infertile women with repeated implantation failure. Am J Reprod Immunol. 2017;78:e12719.

22. Cicinelli $E$, Matteo $M$, Tinelli $R$, Lepera A, Alfonso $R$, Indraccolo $U$, et al. Prevalence of chronic endometritis in repeated unexplained implantation failure and the IVF success rate after antibiotic therapy. Hum Reprod. 2015; 30:323-30.
23. Meyer WR, Castelbaum AJ, Somkuti S, Sagoskin AW, Doyle M, Harris JE, et al. Hydrosalpinges adversely affect markers of endometrial receptivity. Hum Reprod. 1997;12:1393-8.

24. Seli E, Kayisli UA, Cakmak H, Bukulmez O, Bildirici I, Guzeloglu-Kayisli O, et al. Removal of hydrosalpinges increases endometrial leukaemia inhibitory factor (LIF) expression at the time of the implantation window. Hum Reprod. 2005;20(11):3012-7.

\section{Publisher's Note}

Springer Nature remains neutral with regard to jurisdictional claims in published maps and institutional affiliations.
Ready to submit your research? Choose BMC and benefit from:

- fast, convenient online submission

- thorough peer review by experienced researchers in your field

- rapid publication on acceptance

- support for research data, including large and complex data types

- gold Open Access which fosters wider collaboration and increased citations

- maximum visibility for your research: over $100 \mathrm{M}$ website views per year

At BMC, research is always in progress.

Learn more biomedcentral.com/submissions 